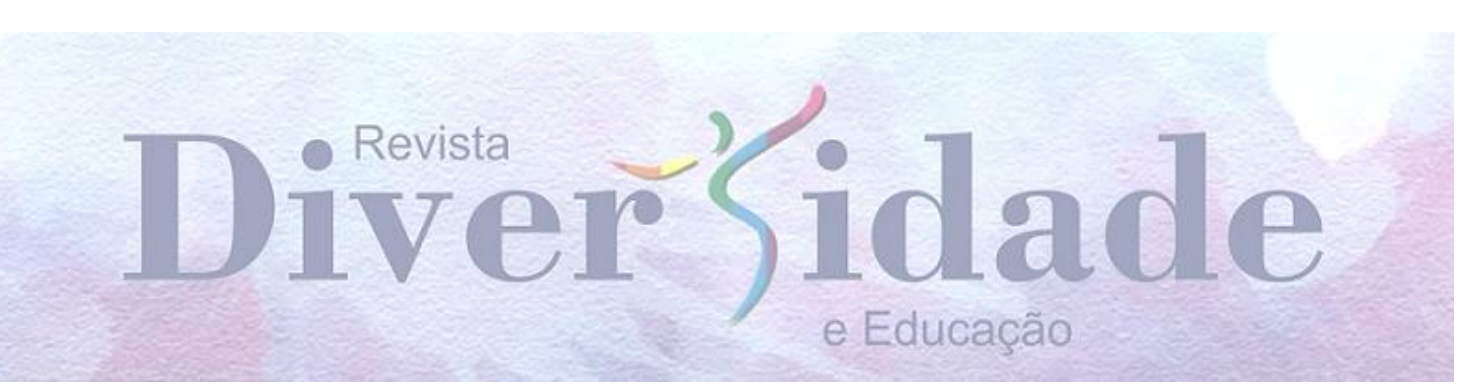

\title{
CORPO, SEXUALIDADE E GÊNERO: VERDADES IMBRICADAS AO ENSINO DE CIÊNCIAS E DE BIOLOGIA
}

\author{
CUERPO, SEXUALIDAD Y GÉNERO: VERDADES IMBRICADAS A LA \\ ENSEÑANZA DE CIENCIAS Y DE BIOLOGÍA \\ BODY, SEXUALITY AND GENDER: TRUTHS IMBRICATED TO THE \\ TEACHING OF SCIENCE AND BIOLOGY
}

\author{
André Morando1 \\ Nadia Geisa Silveira de Souza2
}

\section{RESUMO}

Neste artigo, problematizamos e discutimos as práticas discursivas vinculadas à produção do corpo e da sexualidade nos cursos de Licenciatura em Ciências Biológicas. Examinamos publicações que trazem relatos de experiências pedagógicas de graduandos ligados(as) ao PIBID e aos estágios de docência. Essas publicações estão presentes nas atas de dois importantes eventos científicos: ENPEC e ENEBIO. Inspirados pelos estudos foucaultianos nas suas vertentes pós-estruturalistas, buscamos conhecer os discursos colocados em ação para ensinar sobre o corpo e a sexualidade em sala de aula. Embora os autores entendam e defendam a necessidade de uma abordagem que trate da dimensão social relativa ao corpo e à sexualidade, principalmente, relacionada com as experiências de vida dos alunos, o processo de ensino-aprendizagem continua associado aos discursos biológicos, da anatomia e da fisiologia, e médicos com a finalidade de prevenção de doenças e da gravidez.

PALAVRAS-CHAVE: Ciências Biológicas. Corpo. Sexualidade. Eventos

Científicos

\section{RESUMEN}

En este artículo, problematizamos y discutimos las prácticas discursivas vinculadas a la producción del cuerpo y de la sexualidad en los cursos de Licenciatura en Ciencias Biológicas. Examinamos publicaciones que traen relatos de experiencias pedagógicas de graduandos vinculados al PIBID ya las prácticas de docencia. Estas publicaciones están presentes en las actas de dos importantes eventos científicos: ENPEC y ENEBIO. Inspirados por los estudios foucaultianos en sus vertientes post-estructuralistas, 
buscamos conocer los discursos puestos en acción para enseñar sobre el cuerpo y la sexualidad en el aula. Aunque los autores entienden y defienden la necesidad de un enfoque que trate de la dimensión social relativa al cuerpo ya la sexualidad, principalmente, relacionada con las experiencias de vida de los alumnos, el proceso de enseñanza-aprendizaje sigue asociado a los discursos biológicos, la anatomía y la fisiología, y médicos con la finalidad de prevención de enfermedades y del embarazo.

PALABRAS-CLAVE: Ciencias Biológicas. Cuerrpo. Sexualidad. Eventos Científicos

\begin{abstract}
In this paper, we problematize and discussed the discursive practices linked to the production of the body and of sexuality of Biological Sciences teaching formation courses Biological Sciences. We examine publications that bring reports of pedagogical experiences of undergraduates connected to PIBID and the lecturing stage in the teaching education. These publications are present in the annals of two important scientific events: ENPEC and ENEBIO. Inspired in foucaultian studies on your poststructuralism pespective's, We seek to know, in this publications, the discourses are put in action in the classroom, for teach about the body and the sexuality. Although the authors understand and defend the need the social approach relative about the body and the sexuality, especially, linked to student's life experiences, the teaching-learning process to be continues associated with biological discurses, of anatomy and the fisiology, and medical discurses aim to prevention of disease and the pregnancy.
\end{abstract}

KEYWORDS: Biological Sciences. Body. Sexuality. Scientific Events

\title{
Introdução
}

Neste artigo, problematizamos as verdades e as técnicas colocadas em funcionamento no processo de ensino-aprendizagem ao ser abordado o corpo, a sexualidade e o gênero no Ensino de Ciências e de Biologia. Em nossos estudos, o corpo tem sido entendido como efeito das práticas sociais, familiares, médicas, escolares, religiosas e tantas outras, que o objetivam e o subjetivam 3 ao longo de sua existência. Nesse processo de subjetivação4, o sujeito é ao mesmo tempo alvo e ferramenta das ações exercidas por tais práticas. A constituição do sujeito se dá a partir da submissão do corpo a um determinado regime de verdades que, através de práticas de si, vão atuar na relação do sujeito consigo (FOUCAULT, 2006). Por exemplo, na

3 Entendemos os processos de objetivação, que constituem um corpo dócil e útil, e de subjetivação, que constituem um sujeito preso a uma identidade, como contínuos e provisórios (FOUCAULT, 1993; 1996). 4 Consideramos o Sujeito como constituído através de práticas, efeito de um processo de subjetivação. Ver Ditos e Escritos V, 1984 - O Retorno da Moral em Foucault (2006). 
produção de um tipo de masculinidade vinculada a virilidade, determinados sujeitos, ao se submeterem a um conjunto de regras que irão dizer "o que é" e "como ser" um homem, constituem suas subjetividades imbricadas às verdades dos outros, que tomam para si, agindo sobre si mesmos e configurando suas identidades. Todavia, ao mesmo tempo em que, no campo social, atuam uma multiplicidade de forças direcionadas ao governo dos corpos, em seus espaços de "liberdade", os corpos também resistem a determinadas regras, produzindo outras verdades e modos de existência. Esses movimentos de submissão e de resistência configuram-se como "lutas" produtoras de rearranjos nas subjetividades e na cultura que se produzem e transformam.

Dessa perspectiva, somos efeitos das ações exercidas pelos outros e por nós mesmos que se imbricam no e a partir do corpo - campos de inscrição dos acontecimentos e de emergência dos seus efeitos (FOUCAULT, 1993). O gênero e a sexualidade sedimentam, no corpo, a historicidade de disputas e organizam as posições que os sujeitos devem ocupar na sociedade, os modos de vestir e falar, os prazeres, os hábitos e os cuidados, p.ex., produzindo o corpo. Assim, o corpo não tem uma essência natural, mas adquire forma naquilo que sedimenta das práticas de poder em sua "carne", tornando-se corpo.

Produzir o corpo a partir do disciplinamento das suas condutas vem sendo a base, desde a modernidade, das instituições disciplinares como a escola, o quartel, a família, a igreja. Nessas instituições atua-se no corpo através de diferentes técnicas de poder: a distribuição dos espaços, o esquadrinhamento do corpo, a repetição de exercícios, o controle do tempo [etc]. Investe-se no corpo num exaustivo e ininterrupto ritual de vigilância e de adestramento, resultando num efeito duradouro na vida do(s) sujeito(s) (FOUCAULT, 1987). Os "bons" hábitos ou comportamentos são exemplos de efeitos que produzem sujeitos docilizados e úteis à sociedade. Na escola, vigia-se e adestra-se os corpos e os comportamentos, com a finalidade de produzir o "bom aluno" e a "boa aluna".

Esse processo é ao mesmo tempo permanente e mutável, conforme as finalidades de cada instituição e época, necessitando de adaptações e mudanças conforme a situação. As matérias escolares, a seriação, a organização do tempo - em períodos, o horário da merenda, o horário do banheiro e dos conteúdos são exemplos, de estratégias

5 Nos referimos ao campo como o espaço de relações e "lutas". É no corpo que tais lutas acontecem, delas têm sua proveniência e é no corpo que emergem novas lutas e possibilidades de estar no mundo. Assim, não há como pensar em corpo sem história e história para além do corpo. 
de poder que vão investir continuamente, na produção dos sujeitos-alunos. Conforme a teoria de ensino-aprendizagem e/ou o modelo de ciência as técnicas pedagógicas podem partir da visão de que existe uma progressividade no nível de complexidade e dificuldade que vai da letra à sílaba, dos átomos às moléculas, das organelas à célula etc. Contudo, tais técnicas escolares, implicadas em relações de saber/poder6, não são neutras, têm finalidades e produzem efeitos nas formas de conhecer, pensar e agir dos e das estudantes.

Desse ponto de vista, poderíamos nos interrogar, por exemplo, sobre a(s) finalidade(s) das disciplinas de Ciências e de Biologia acerca do ensino dos temas corpo e sexualidade. Que corpo essas disciplinas produzem?

Para pensarmos acerca dessa questão e da legitimação das regras e verdades que regem o que, como e quem fala sobre o corpo nessas disciplinas, examinamos artigos aceitos em dois eventos científicos dessas áreas, o que será discutido ao final deste artigo.

\section{O corpo efeito: a escolarização, a discursividade científica, a sexualidade, ...}

O corpo é constituído a partir de uma "matriz orgânica" que, historicamente, vem sendo transformada nas e pelas ações humanas imbricadas a relações de saber/poder em funcionamento em diversas instâncias sociais. Se quisermos conhecer o corpo precisamos examinar os processos constitutivos de suas marcas, presentes nos corpos que nos tornamos. Olhar as práticas culturais cujos efeitos estão presentes nos modos de sentar-se, andar, cuidar ou não de si, respirar, sentir prazer e desejos, de vestir.

Em diferentes instâncias sociais inúmeras convenções culturais são inscritas no corpo. As roupas que meninos e meninas devem vestir, as cores apropriadas, os comportamentos esperados etc. vão produzindo formas de ser sujeito, feminino ou masculino. Na escola, tais "verdades" chegam por meio de várias práticas sociais - as disciplinas curriculares, o bullyng, os livros didáticos, os espaços generificados como a fila dos meninos e das meninas, o banheiro, os esportes etc. - que irão operar na produção de tipos de existência a partir da (a)normalização dos corpos.

6 Segundo Foucault (1987), temos que entender que o poder e o saber estão implicados, não há relação de poder que não constitua um campo de saber e não um saber que não produza relações de poder, o sujeito que conhece, o objeto a conhecer, as modalidades de conhecimento são tantos outros efeitos de tais implicações. 
Controlar para normalizar configura a história da escolarização, a escola moderna foi criada como uma instituição para investir [e investe] suas ações na produção de certos sujeitos. Para produzir um corpo submetido ao sistema e extrair dele o máximo de produtividade, desde o século XIX, funciona uma rede instituições (o quartel, as fábricas, a escola, o hospital, o asilo), onde a existência humana foi aprisionada e a identidade e o corpo foram sendo forjados pelas técnicas disciplinares, a fim de que aquele corpo se tornasse um soldado, aluno, paciente, cidadão, louco etc., um sujeito dócil e útil para o sistema e o trabalho. Contudo, o controle do corpo e da sua vida não se limitou ao interior das instituições, mas também se controlou suas atividades, gastos, saúde, moradia, experiencias sexuais (FOUCAULT, 1987)

Segundo Foucault (2015), desde o século XVIII, a sexualidade encontra-se imbricada a mecanismos de controle direcionados ao corpo (família, escola, religião, medicina) e de governo regulamentadores dos fenômenos das populações. A produção e controle da sexualidade atua em dois domínios: do corpo (a masturbação, os papéis sexuais, os desejos, p.ex.) e dos processos biológicos (reprodução, natalidade, doenças, p.ex.). O controle da sexualidade articula efeitos disciplinadores7 e regulamentadores, pois ela "está exatamente na encruzilhada do corpo e da população" (FOUCAULT, 2005, p. 300). Tal articulação tinha como finalidade a produção de um alinhamento da sexualidade [prazeres e desejos do corpo] com a procriação [processo biológico da população].

Nas práticas escolares, o "sexo", a partir da noção científica de que existe um sexo biológico definidor das identidades sexuais e de gênero, dos prazeres e desejos, integra um dispositivos da sexualidade, que opera em diversos espaços da escola e com diferentes técnicas, para o controle e normalização das condutas sexuais e dos gêneros.

No Brasil, desde o início do século XX, várias iniciativas buscaram inserir a educação sexual, no currículo escolar, desde as concepções higienistas do controle da masturbação e das doenças venéreas até a educação para a maternidade, voltada às

7 A partir de Foucault, a disciplina é efeito da ação de forças ou técnicas de poder que operam na sistematização do tempo, do espaço, dos movimentos e que irão atuar sobre o comportamento, os gestos, os corpos. A disciplina visa o maior aproveitamento ou produtividade do corpo, tornando-o dócil, "adestrado" e moldado a partir de um suposto padrão (REVEL, 2005). Podemos dizer também, que se trata de uma ação sobre outras ações, em desníveis de poder, tal como a do professor-aluno, médicopaciente.

8 Estamos usando dispositivo como uma rede heterogênea cujos elementos sociais, discursivos ou não, articulam-se estrategicamente, conforme o momento histórico e a finalidade de resposta a uma urgência. (FOUCAULT, 1993, p. 244). 
meninas, bem como ações direcionadas para os reforços dos supostos papéis sociais para homens e mulheres (RIBEIRO, 2002).

Todavia, antes mesmo de tais iniciativas, a escola enquanto instituição disciplinar já operava (e opera) como uma maquinaria de procedimentos direcionados ao corpo dos sujeitos, integrando uma rede de práticas generificadas para a produção dos sujeitos/alunos.

$\mathrm{Na}$ escola, funcionam e se articulam as técnicas pedagógicas e a distribuição dos espaços para o controle, modulação, vigilância e disciplinamento do corpo, tanto dos discentes quanto dos docentes. A condução das condutas e a incorporação das "verdades" exigem vigilância e intervenções permanentes. Para tanto, os espaços são distribuídos e demarcados, na sala de aula cada um num lugar, no pátio as filas são generificadas, os espaços hierarquizados etc. A arquitetura da escola tem como projeto a visibilidade, ser e sentir-se vigiado/a, configurando-se numa instituição panóptica.

O processo de escolarização, ao atuar sobre as condutas dos sujeitos/alunos, controla e produz gestos, hábitos, posturas, valores, ritmos, pensamentos etc. A escola integra uma rede de instituições criada com a finalidade de submeter e docilizar a diversidade dos corpos, produzindo, através de técnicas homogeneizantes, um aluno(a) "normal”, um decalque de um modelo adequado às verdades de um dado projeto social, no caso aqui em discussão, relativas ao corpo, o gênero e a sexualidade (SOUZA, 2016; RIBEIRO, 2002).

O que viemos tecendo até aqui, vai na direção de chamar a atenção e problematizar o conjunto de técnicas que funcionam e articulam-se nos espaços da escola, com a finalidade de produzir sujeitos docilizados. Sobre os investimentos da disciplina no corpo dos alunos e alunas, Guacira Louro (2000), irá nos dizer que ao mesmo tempo em que se disciplina o corpo se disciplina a mente. A respeito do disciplinamento do corpo-mente. Portocarrero (2004), nos fala que os gestos e o corpo são colocados em relação por uma perspectiva do melhor aproveitamento, agilidade e eficiência. Essa relação condiciona o corpo/mente a resolver a situação pedagógica com o mínimo gesto, em menor tempo e com êxito. Ao se disciplinar corpo/conduta esperase que cada sujeito seja capaz de autogerir-se, autocontrolar-se e autogovernar-se, portanto, ao agir no corpo o poder conduz as condutas e os pensamentos, o que Foucault (1987; 2005) irá denominar de biopoder no nível do corpo.

$\mathrm{Na}$ escola, atuam ainda estratégias organizadoras do conhecimento e dos modos de aprender, as disciplinas escolares, ligadas a campos de conhecimento e resultantes de 
demandas sociais, políticas educacionais etc. As disciplinas configuram-se através de processos de transposição de saberes dos campos científicos dos quais derivam para a produção de um conhecimento escolar. Além disso, atua um controle "interno", uma seleção dos conhecimentos que serão transmitidos no espaço das salas de aula. Para Elizabeth Macedo e Alice Lopes (2002):

\begin{abstract}
A disciplina escolar é uma instituição social necessária, pois traduz conhecimentos que são entendidos como legítimos de serem ensinados às gerações mais novas, organizam o trabalho escolar, a forma como professores diversos ensinarão, em sucessivos anos, a milhares de alunos, orientam como professores são formados, como os exames são elaborados, como os métodos de ensino são constituídos, como se organiza o espaço e o tempo escolares (ibid., p.83).
\end{abstract}

Nesse sentido, entendemos as disciplinas escolares como estratégias de poder/saber que, ao organizar e, em certa medida, "traduzir" o conhecimento científico, têm a finalidade de organizar e controlar os modos e os "objetos" a conhecer no processo de ensino-aprendizagem, configurando tipos de subjetividades. Para tal finalidade utiliza-se de outras técnicas, tais como o livro didático, a ordenação dos conteúdos, as práticas pedagógicas, as avaliações etc. (XAVIER; FREIRE; MORAIS 2006).

Estratégias de biologização do corpo, da sexualidade e do gênero :o Ensino de Ciências e de Biologia

Nesse cenário escolar, as práticas docentes, os discursos verdadeiros, as disciplinas curriculares e o livro didático, p.ex., integram uma rede de relações heterogêneas, um dispositivo com finalidades estratégicas. Ensinar certos "conteúdos" escolarizados, através de relações de saber/poder, para produzir tipos de sujeito/aluno(a) necessários às urgências e demandas dos projetos sociais, econômicos e políticos em vigor num certo momento. Dessa perspectiva, quando uma disciplina é criada e "entra para o currículo escolar" passa a fazer parte de uma rede de elementos sociais e a ter uma finalidade estratégica, atender a uma urgência.

Para ilustrar, no caso da Biologia, trazemos a disciplina Biologia Educacional, criada no Brasil dos anos de 1930. A partir da Reforma de Francisco Campos, em 1931, a Biologia Educacional, exerceu papel importante na formação de professoras do ensino 
primário. As expectativas políticas e econômicas voltadas para o desenvolvimento do país não estavam alinhadas com as condições de vida da população brasileira daquele período. A maioria era pobre, analfabeta e doente, acometida principalmente por verminoses, hanseníase e tuberculose. Os maiores índices de morbidade estavam nos sertões do Brasil, esquecidos pelas políticas públicas. Assim, formar professoras e enviá-las para os interiores do país, onde poderiam disseminar conhecimentos sobre os cuidados com o corpo, a higiene, a alimentação, as parasitoses e a criação das crianças a partir de uma maternidade medicalizada, funcionaria como uma estratégia que "resolveria" a um baixo custo para o Estado, a urgência daquelas demandas sociais e econômicas (MORANDO, SOUZA 2019; VIVIANI, 2007).

Olhar para as disciplinas escolares, Ciências e Biologia, como elementos de um dispositivo pedagógico é entendê-las como estratégias produtoras de sujeitos e subjetividades. Isso, nos move a pensar que nem suas discursividades e objetos, nem sua estabilidade nos currículos oficiais das escolas são "naturais" e universais, mas sim invenções de grupos sociais num certo momento. Para um movimento de problematizar práticas homogeneizantes e hegemônicas, nas práticas escolares, torna necessário conhecer como tais práticas e seus objetos foram construídos historicamente. Uma dessas produções, do campo Biológico, integrante do ensino de Ciências e de Biologia tem sido a noção biológica e universalizante de organismo para o estudo do corpo uma materialidade orgânica cuja composição, funcionamento e respostas anatomofisiológicas, genética, bioquímica é igual em todas as pessoas, no caso do "sexo" o funcionamento funda-se numa matriz reprodutiva e heterossexual. As discursividades do corpo, que circulam no ensino dessas disciplinas, ancoram-se também nos saberes biomédicos, cuja noção universal de organismo biológico, gera prescrições homogêneas para os hábitos de higiene, a prevenção de doenças e os riscos de uma sexualidade descontrolada e desvinculada da reprodução (SILVA, 2017; TRIVELATO, 2005; MACEDO, 2005; SOUZA, 2001).

A Biologia tem uma história, ela não é natural, mas sim naturalizada (SANTOS, 2000). O Ensino de Biologia, ao naturalizar práticas discursivas que desvinculam o corpo dos seus acontecimentos culturais, associa-o a uma organicidade que interliga células, tecidos, órgãos e forma sistemas (ELIZABETH MACEDO, 2005). Para Silvia Trivelato "no ensino médio o corpo humano se "espreme" nas células e se estudam as funções celulares e moleculares, que já não são exclusivas do corpo humano, mas universais para os seres vivos" (TRIVELATO, 2005, p. 122). Tais conhecimentos 
desconsideram a historicidade, as relações e implicações culturais na configuração do corpo e a possibilidade de reconhecer e pôr em discussão a existência das diferenças. Produzem uma visão de corpo e de subjetividade como manifestações de uma essência, uma natureza humana com origem comum e um desenvolvimento e existência universais.

Ao falar acerca da "economia política" da verdade, na sociedade ocidental, Foucault (1993) vai nos dizer que a verdade é uma invenção deste mundo, centrada na forma do discurso científico e nas instituições que a produzem, estando submetida a permanente incitação, difusão, consumo e sendo produzida e transmitida, não exclusivamente, mas de forma dominante por alguns grandes mecanismos políticos ou econômicos, como as universidades, o exército, a mídia.

\section{Eventos científicos: controle e difusão do que e como ensinar sobre o corpo}

\section{em artigos}

Nessa direção, entendemos os eventos científicos como espaços de legitimação de determinadas regras e verdades, no caso o que e como ensinar sobre o corpo. Assim, fomos analisar artigos publicados no Encontro Nacional de Pesquisa em Educação em Ciências - ENPEC e no Encontro Nacional de Ensino em Biologia - ENEBIO9. Pensar os artigos, apresentados nas atas, como efeitos de regras e de verdades que atuaram selecionando e autorizando os discursos verdadeiros a serem divulgados, levou-nos a olhar para as práticas docentes legitimadas a ensinar sobre o corpo através das Ciências Biológicas. Olhamos para os artigos na perspectiva de pensar nas verdades e no corpo que tal campo produz quando coloca em jogo categorias como o corpo, o gênero e a sexualidade?

Nosso interesse se localiza no Ensino Superior, nos cursos de Licenciatura em Ciências Biológicas. Por essa razão, selecionamos publicações que tratam de relatos de experiências de estudantes do Programa Institucional de Bolsas de Iniciação à Docência - PIBID e da graduação durante seu estágio de docência nas disciplinas de Ciências e de Biologia da Educação Básica. Olhamos tais produções com o intuito de conhecer como as práticas discursivas relacionadas ao corpo, ao gênero e à sexualidade atuam na

9 Esses eventos consolidaram-se no campo do Ensino de Ciências [multidisciplinar] e de Biologia com um número crescente de submissões exponencialmente. O ENPEC iniciou em 1997 e o ENEBIO em 2005. 
formação inicial desses e dessas futuras(os) docentes. Isso, talvez crie condições para construímos um "cenário" e um diagnóstico daquilo que vem sendo produzido do corpo na formação inicial de professoras e professores.

Os artigos examinados 10 servem como fontes que nos dão pistas das práticas investidas na produção de tipos de sujeitos através da abordagem do corpo. Examinamos essa produção a partir da articulação do Ensino de Biologia e Ciências com o corpo, o gênero e a sexualidade, desde o início dos Eventos até a última ocorrência11. Dos 63 artigos que abordavam o corpo relacionado ao gênero e à sexualidade, nas disciplinas de Ciências e Biologia, somente 6 artigos foram escritos por autores vinculados ao PIBID ou ao estágio supervisionado de docência e ao ENEBIO. Embora não seja esta a discussão aqui, essa "limitada" produção e divulgação nos fez pensar em condições associadas as instituições científicas: a posição periférica dos temas corpo, sexualidade e gênero nos currículos dos cursos de Licenciaturas em Ciências Biológicas; a não problematização do tema por parte dos e das estudantes de Licenciatura; e o não aceite de artigos que "fogem" à perspectiva do Evento. As técnicas de exame, para seleção às regras do Evento, controlam e legitimam os discursos verdadeiros colocados em circulação através da divulgação e "moldam" a forma e o conteúdo dos artigos. Isso, significa dizer também que tantas outras produções e experiências foram realizadas, mas que talvez se encontrem à "margem" de tais instâncias.

As experiências pedagógicas relatadas mostram as maneiras regradas e pensadas colocadas em ação a partir de discursos verdadeiros e proposições em circulação - em documentos orientadores como os Parâmetros Curriculares Nacionais (BRASIL, 1998; 2000), nas políticas públicas, nas publicações acadêmicas, nos campos científicas, [etc.] -, as quais criam grades de interpretação e ações [saber/poder] direcionadas e colocadas em funcionamento nas "práticas" escolares. Ao nos falar do papel concreto das práticas na constituição dos sujeitos e dos objetos na imanência de um campo de conhecimento,

10 A seleção dos artigos nas páginas dos eventos ocorreu a partir de palavras chaves e do título, da leitura do resumo e da leitura do artigo na íntegra. Na busca utilizamos os descritores: corpo, gênero e sexualidade, os artigos que apresentavam uma dessas palavras foram salvos em uma pasta virtual. Nessa etapa da seleção encontramos 142 artigos no ENPEC e 69 no ENEBIO, totalizando 211 artigos, desses 63 tratavam do corpo relacionado ao gênero e à sexualidade nas práticas pedagógicas das disciplinas de Ciências e Biologia. Por fim, selecionamos 6 artigos escritos por autores vinculados ao PIBID ou ao estágio supervisionado de docência, vinculados ao ENEBIO. Mantivemos os nomes dos autores no anonimato.

11 O recorte do ENPEC foi do ano de 1997 até 2017 e o ENEBIO do ano de 2005, até o ano de 2016, visto que os Anais do Evento de 2018 ainda não foram disponibilizados. Em 20 anos o ENPEC teve 7500 publicações e em 11 anos o ENEBIO teve 2518 publicações. 
Foucault (2006, p. 238), destaca que as práticas "concebidas ao mesmo tempo como modo de agir e de pensar que dão a chaves de inteligibilidade para a constituição correlativa do sujeito e do objeto". Olhar as práticas, nessas disciplinas, pode nos possibilitar conhecer as "verdades" imbricadas à produção do corpo e aos modos de vivenciar o corpo. Segundo Rosa Fischer (2001), a análise dos discursos na perspectiva foucaultiana, deve se manter no nível das palavras, do que está dito. Recusa a busca por sentidos "escondidos" e procura expor a complexidade do que está dito. Nessa direção, examinamos a problematização e o referencial teórico adotado para subsidiar o artigo e como esses saberes operam no relato da experiencia pedagógica e selecionamos e destacamos trechos dos artigos, que, ao nosso ver, funcionam como discursos verdadeiros e nos ajudam a conhecer determinadas práticas discursivas.

\section{Como se fala do corpo, da sexualidade e do gênero nos artigos}

A leitura dos artigos levou-nos a organizá-los em dois grupos, A e B, de acordo com o tema abordado nas disciplinas de Ciências e Biologia. No grupo A estão três artigos que têm como tema central a abordagem da sexualidade. No grupo B encontramse três artigos que buscam problematizar o ensino do corpo, sendo que a sexualidade aparece difusa e periférica nas narrativas. Em ambos os grupos, o gênero ou questões associadas às identidades de gênero não aparecem. Assim, mesmo se abordando a sexualidade e/ou o corpo, ser "homem" ou ser "mulher", masculino ou feminino não são características vistas como problemas, uma vez que indicam ser entendidas como algo da natureza biológica humana. Esse "silenciamento" relativo ao gênero pode nos mostrar um efeito das verdades do discurso biologizante, no qual os objetos em discussão tornam-se conhecidos e pensados através das e pelas "lentes" da biologia. No caso do estudo do corpo, as características das genitálias naturalmente definirão os gêneros, masculino e feminino, aqueles que fogem desta norma tornam-se os “anormais", os desviantes. As verdades associadas a tal visão não é novidade, contudo vem configurando um saber que, circula no campo social, autorizando uma rede de intervenções direcionadas aos corpos "desviantes”, inclusive ações violentas.

Outro aspecto, presente nas narrativas dos dois grupos, refere-se à dificuldade de abordar os temas corpo e sexualidade. No grupo A, tal dificuldade está relacionada aos tabus, lidar com preconceitos e à abordá-la de forma ampla e multicultural. Tal como aparece nos excertos: 
A despeito desta importância, é fato constatado e diversas pesquisas que a abordagem da sexualidade na sala de aula configura-se como um desafio para os professores, sendo evitada por muitos, ao tratar de tabus, preconceitos, questões morais e religiosas, de cunho polêmico ou constrangedor. (Artigo A, 2012).

Ainda que haja deficiência na formação docente para a abordagem de questões de sociais somada à dificuldade de manter a transversalidade do tema, a sexualidade deve ser abordada para além da perspectiva biológica, incluindo toda variedade de aspectos relacionados à temática (Artigo A1, 2016).

No grupo B, a dificuldade para a abordagem do corpo relaciona-se a forma de vincular o corpo "do livro didático" ou "da Biologia” com o corpo dos e das estudantes. Em um dos artigos tal problema configura os objetivos da experiência pedagógica apresentada e discutida. Essa dificuldade aparece nos seguintes excertos:

Temos como objetivo: (i) analisar situações e materiais de ensino, problematizando-as a partir de aspectos relacionados à fragmentação e/ou integração do ensino, ao uso de analogias mecanizadas e simplistas e à representação do corpo humano com cores e proporções irreais; e (ii) apresentar propostas de abordagens do ensino do corpo humano de maneira contextualizada, integrando os sistemas e suas funções com o intuito de levar os estudantes a compreender o corpo como uma unidade inserida no contexto social do aluno (Artigo $\mathrm{B}, 2014)$.

No caso específico do ensino de ciências os temas relacionados ao corpo humano temos enfrentado um grande desafio. Quando nos questionamos "Que corpo Humano cabe no ensino de Ciências?" pretendemos romper com um ensino no qual o corpo humano frequentemente é abordado de forma cartesiana, fragmentada e, portanto, distante da representação multidimencional essencial para a construção das relações com o próprio corpo e o corpo do outro, e, por conseguinte, com os mais variados corpos presentes na natureza. (Artigo B, 2016).

Os artigos do grupo B, apresentam preocupações relativas às abordagens do corpo a partir da visão da biologia, desconsiderando as vivencias dos estudantes com seus corpos e a diversidade de corpos produzidos nas culturas. Como uma forma de articular o biológico ao cultural, os futuros docentes convergem no entendimento de que o corpo deve ser tratado e (re)pensado a partir das vivências e experiências dos alunos e alunas. Para tanto, ambos os grupos propõem como estratégias de ensino-aprendizagem atividades introdutórias com perguntas e depois jogos, filmes, dinâmicas em grupo, produção de cartazes, etc. Além disso, realizam atividades que procuram relacionar o 
funcionamento do corpo com o meio, por exemplo, os sentidos [audição, paladar, olfato, paladar e visão] a diferentes experimentações, tal como sentir odores com os olhos vendados, a fim de estimular uma possível memória. No entanto, o desenvolvimento do estudo vai ocorrer a partir de explicações biológicas sobre o funcionamento do cérebro para as diferentes formas de interpretar o ambiente. Queremos dizer com isso que, embora seja percebido por parte dos futuros docentes que o funcionamento do corpo se produz e está imbricado à interrelação com o meio, as abordagens ainda se mantém atravessadas e marcadas pelas verdades da biologia. Tais situações pedagógicas nos fazem pensar que, se por um lado, ocorre uma certa continuidade na abordagem biologicista do ensino do corpo, por outro, estão emergindo novos conhecimentos associados ao corpo, enquanto um fenômeno biossocial, gerando descontinuidades entre o conhecimento e a ação pedagógica.

Isso, também aparece nos artigos que tratam especificamente da sexualidade, onde, de modo geral, os autores e as autoras buscam abordar o tema num sentido mais amplo, abrangendo o biológico e as aprendizagens em diferentes instâncias, como na família e no grupo de amigos. Para colocar tal pensamento em ação, utilizam o que chamam de aprendizagem significativa, sem referência a autores. Contudo, a noção de "significar" parece estar associada a elementos da vida cotidiana dos alunos e das alunas, o que vai dar sentido ou não ao que está sendo ensinado. Para tanto, as experiencias pedagógicas iniciam com questões prévias sobre o tema através de perguntas anônimas, posteriormente lidas e debatidas com o grupo. A partir desse movimento, ocorrem atividades explicativas centradas na biologia e na memorização dos "novos conhecimentos", o que se dá através das atividades citadas anteriormente. Ao final, busca-se examinar o que foi “aprendido", p.ex., a partir da produção de cartazes explicativos ou de um novo questionário. Para ilustrar apresentamos os seguintes excertos:

A partir do diagnóstico sobre os conhecimentos prévios dos alunos e suas respectivas dúvidas, realizou-se uma apresentação (aula expositiva dialogada), com esquemas e ilustrações, demonstrando a importância dos cuidados sexuais, gravidez na adolescência, as doenças sexualmente transmissíveis, mudanças no corpo, métodos contraceptivos e higiene (Artigo A2, 2016).

No primeiro contato, a proposta de trabalho foi apresentada aos estudantes para que fossem instigados a participar das atividades. A fim de identificar suas concepções sobre a temática, cada aluno recebeu um questionário fechado onde, além de indicar seu gênero e 
sua idade, respondeu: se já teria iniciado a vida sexual; se conversa com alguém sobre sexualidade; o que entende sobre sexualidade; se conhece as principais DSTs; e se utiliza proteção durante as relações sexuais. Os estudantes foram informados de que deveriam responder anonimamente, para que se sentissem confortáveis a fazê-lo de forma séria e honesta (Artigo A1, 2016).

A elaboração dos cartazes pelos estudantes teve como objetivo principal transformá-los em verdadeiros agentes multiplicadores de conhecimento sobre as DSTs durante a Feira de Ciências. Neste caso, a participação direta do estudante em todas as etapas do trabalho [...] possibilitou ao educando se aproximar, interagir e se apropriar do objeto de estudo, condições essenciais na construção do conhecimento (Artigo A1, 2016).

Nessas abordagens, vemos o funcionamento de elementos do dispositivo da sexualidade - a confissão, o fazer falar e examinar $o$ que se pensa e conhece do seu corpo, como se age nele - para, através do saber/poder biológico e biomédico, conduzir os pensamentos e as condutas em relação ao corpo, controlando seus prazeres e desejos, enfim a "sexualidade".

Embora os artigos discutam a sexualidade a partir das dimensões biológica e social, as discussões realizadas com os alunos e as alunas centram-se nos riscos à saúde, nas infecções pelo vírus HIV, na AIDS, nas DSTs e na gravidez na adolescência. Assim, novamente há um descompasso entre a teorização acerca da sexualidade e as práticas em ação no ensino relacionado à sexualidade, visto que ainda está centrado nas verdades biomédicas direcionadas ao controle da sexualidade e à prevenção de doenças e da gravidez, a semelhança daquelas propostas que entraram no cenário educacional dos anos 80 do século passado.

Examinar as experiências pedagógicas dos futuros docentes do Ensino de Ciências e de Biologia, mostrou-nos que as suas práticas provêm e encontram-se circunscritas aos discursos verdadeiros da biologia e da medicina, embora encontrem-se interpelados e em "luta" com verdades de outras perspectivas, as quais tratam da dimensão social e cultual do corpo e da sexualidade.

\section{Conclusão}

Ao rever o que viemos tecendo, até aqui, algumas considerações dizem respeito as práticas discursivas que nos produzem enquanto professores nas disciplinas de Ciências e Biologia. Embora, desde o final dos anos 90 do século passado, documentos 
orientadores 12 e normatizadores 13 já propusessem que a educação escolar deveria tomar como princípios os Direitos Humanos, o multiculturalismo e o respeitos às diferenças e que a orientação sexual deveria ser um tema transversal (PCNs), mesmo com ressalvas ao enfoque biomédico, chamou-nos a atenção o predomínio, ainda hoje, das verdades ligadas aos campos da biologia e da medicina nas abordagens do corpo e da sexualidade, e a ausência ou o "silenciamento" em torno do gênero no Ensino de Ciências e de Biologia. Tais práticas de ensino não criam condições para os alunos e alunas falarem e pensarem acerca dos seus corpos, prazeres, desejos, cuidados ou não, questões provenientes das suas vivencias, construindo um conhecimento de si e interrogando-se sobre as verdades implicadas nas maneiras de agir em relação a si e aos outros Os discursos verdadeiros da biologia e da medicina, especialmente a partir do século XIX, articularam-se e estreitaram seus vínculos com o poder com a finalidade de controlar e governar os corpos e as vidas das pessoas. Assim, enquanto porta-voz dos discursos científicos no espaço escolar torna-se necessário que nos questionemos acerca das verdades implicadas nas nossas escolhas pedagógicas e os seus efeitos, visto que configuram modos de pensar, agir e subjetividades. Todavia, dentre as experiencias pedagógicas, não podemos deixar de destacar a entrada em "cena", mesmo de forma ainda tímida, de teorizações sobre o corpo e a sexualidade a partir de perspectivas biossociais, produzindo dúvidas, questões e desacomodações relativamente às abordagens instituídas, centradas no biológico e na medicina.

\section{Referências}

BRASIL. Ministério da Educação. Parâmetros Curriculares Nacionais Ensino Médio. Brasília, DF, 2000.

BRASIL. Ministério da Educação. Parâmetros Curriculares Nacionais: terceiro e quarto ciclos do Ensino Fundamental ciências naturais. Brasília, DF, 1998.

FISCHER, Rosa Maria Bueno. Foucault e a Análise do Discurso em Educação. Cadernos de Pesquisa, n. 114, p. 197-223, nov. 2001.

FOUCAULT, Michel. A história da Sexualidade I: A vontade de saber. 1. ed. São Paulo: Paz e Terra, 2015. 
FOUCAULT, Michel. A ordem do discurso: aula inaugural no Collège de France, pronunciada em 2 de dezembro de 1970. $3^{\text {a }}$ ed. São Paulo: Edições Loyola, 1996.

FOUCAULT, Michel. Em defesa da sociedade: Curso no Collège de France (19751976). São Paulo: Martins Fontes, 2005.

FOUCAULT, Michel. Ética, Sexualidade, Política. (Coleção Ditos e Escritos V). Rio de Janeiro: Forense Universitária, 2006.

FOUCAULT, Michel. Microfísica do Poder. Rio de Janeiro: Graal, 1993.

FOUCAULT, Michel. Vigiar e punir: nascimento da prisão. Petrópolis, Vozes, 1987.

LOURO, Guacira, Lopes. Corpo, escola e identidade. Educação \& Realidade, Porto Alegre, v. 25, p. 59-76, jul./dez. 2000.

MACEDO, Elizabeth.; LOPES, Alice. Ribeiro. Casemiro. A estabilidade do currículo disciplinar: o caso das Ciências. In: MACEDO, Elizabeth; LOPES, Alice Casimiro. (Org.). Disciplinas e integração curricular. Rio de Janeiro: DP\&A, 2002, v. 1, p. 73-94.

MACEDO, Elizabeth. Esse corpo das ciências é o meu?. In: MARANDINO, Martha; SELLES, Sandra Escovedo; FERREIRA, Marcia Serra; AMORIM, Antonio Carlos Rodrigues. (Org.). Ensino de biologia: conhecimentos e valores em disputa. 1ed.Niterói: EdUFF, 2005.

MORANDO, André; SOUZA, Nadia Geisa Silveira de. A biologia educacional e a higiene escolar na década de 1940: a (in)visibilidade das diferenças na educação brasileira. Textura-Ulbra. V.21, p. 1-23, 2019.

PORTOCARRERO, Vera. Instituição Escolar e Normalização em Foucault e Canguilhem. Educação e Realidade, UFRGS, v. 29, n.1, p. 169-185, 2004.

REVEL, Judith. Michel Foucault: conceitos essenciais. São Carlos: Claraluz, 2005.

RIBEIRO, Paula Regina Costa. Inscrevendo a sexualidade: discursos e práticas de professoras das séries iniciais do Ensino Fundamental. 2002. Tese (Doutorado em Bioquímica) - Programa de Pós-Graduação em Bioquímica, Instituto de Ciências Básicas da Saúde, Universidade Federal do Rio Grande do Sul, Porto Alegre, 2002.

SANTOS, Luis Henrique Sacchi. A biologia tem uma história que não é natural. In: COSTA, Marisa Vorraber. (Org.). Estudos Culturais em Educação: mídia, arquitetura, brinquedo, biologia, literatura, cinema. Porto Alegre: UFRGS, 2000.

SILVA, Elenita Pinheiro de Queiroz. Outras experimentações de corpos, gênero e sexualidades em Ciências e Biologia. In: NORONHA, Claudianny Amorim.; SÁJÚNIOR, Lucrécio Araújo de. (Orgs.). Escola, ensino e linguagens: propostas e reflexões. Natal: EDUFRN, 2017.

SOUZA, Nadia Geisa Silveira de. Discutindo Práticas Implicadas na Produção do Corpo. In: CAMOZZATO, Viviane Castro; CARVALHO, Rodrigo Saballa de; 
ANDRADE, Paula Deporte de. (Org.). Pedagogias culturais: a arte de produzir modos de ser e viver na contemporaneidade. Curitiba: Appris, 2016.

SOUZA, Nadia. Geisa. Silveira. Que Corpo é esse? O corpo na família, mídia, escola, saúde... Tese [Doutorado em Bioquímica]. Porto Alegre: Instituto de Ciências Básicas da Saúde/UFRGS, 2001.

TRIVELATO, Silvia. Que Corpo/Ser Humano habita Nossas Escolas?. In: MARANDINO, Martha; SELLES, Sandra Escovedo; FERREIRA, Marcia Serra; AMORIM, Antonio Carlos Rodrigues de. (Org.). Ensino de Biologia: conhecimentos e valores em disputa. Niterói: EdUFF, 2005.

VIVIANI. Luciana. Maria. A Biologia Necessária: formação de professoras e escola normal. Belo Horizonte: Argvmentvm; São Paulo: FAPESP, 2007.

XAVIER, M. C. F.; FREIRE, A. de S.; MORAES, M. O. A nova (moderna) biologia e a genética nos livros didáticos de biologia no ensino médio. Ciência e Educação. Bauru, v. 12, n. 3, p. 275-289, 2006. 